\title{
Spatial and Temporal Characteristics of Rurality in Urban Suburb Town and Its Driving Factors Based on Land Use Transformation
}

\author{
Zhiheng Yang ${ }^{1}$ and Chenxi Li $\mathbb{D}^{2,3}$ \\ ${ }^{1}$ Institute of Regional Economics, Shandong University of Finance and Economics, Jinan 250014, China \\ ${ }^{2}$ School of Public Administration, Xi'an University of Architecture and Technology, Xi'an 710055, China \\ ${ }^{3}$ Department of Geography, University of Wisconsin-Madison, Madison, WI 53706, USA
}

Correspondence should be addressed to Chenxi Li; lichenxi@xauat.edu.cn

Received 30 June 2020; Revised 2 August 2020; Accepted 11 August 2020; Published 24 August 2020

Academic Editor: Jun Yang

Copyright (C) 2020 Zhiheng Yang and Chenxi Li. This is an open access article distributed under the Creative Commons Attribution License, which permits unrestricted use, distribution, and reproduction in any medium, provided the original work is properly cited.

\begin{abstract}
Rurality highlights the intrinsic differences between urban and rural communities. The comprehensive rurality evaluation index system is difficult to obtain indicators that reflect purely rural or urban characteristics; in addition, most of the data used in the evaluation index system come from statistical data, and the authenticity of the data cannot be guaranteed. Taking 25 towns in Lixia County and Shanghe County in Jinan city as the study area and using land use data and economic statistics data, the rurality evaluation system based on the land use transformation was constructed, the changes of the rurality index and intensity from 2009 to 2015 were calculated, and the driving factors of the rurality were analyzed. The results showed that, from 2009 to 2015, the rurality difference among towns in Lixia County decreased, the rurality difference among towns in Shanghe County increased, the rurality intensity of Lixia County was lower than that of Shanghe County, and the rurality index gap between the two counties was increasing. In 2009, the rurality grade of Lixia County was dominated by weak intensity ( $84.62 \%)$, and the rurality of the county changed greatly in 2015, with a large proportion (76.92\%) still being weak intensity. In 2009, the proportion of relatively strong intensity was dominated (33.33\%) in Shanghe County; in 2015, weak intensity accounted for a large proportion (41.67\%). Changes of rurality intensity in Lixia County and Shanghe County were different. There was a significant correlation between the rurality index and geographical elevation, GDP, and the distance from the center of the town government, the road construction level, the urbanization level, and the education level. This paper can provide an empirical reference for rurality index research.
\end{abstract}

\section{Introduction}

Under economic and social development transformations, land use transformation refers to the transformation process of regional land use form in a specific period $[1,2]$. Land use transformation research is an important scientific issue of the global land plan, and it integrates the time scale and historical background of social and environmental changes $[3,4]$. As land is the carrier of rural landscape, rural production, and life, the characteristics of rural land use are indicators of rural development [5-8]. Rural is an important part of China's urban and rural construction, and rural development directly affects the process and effectiveness of China's new urbanization construction. In recent years, rural geography research presents the characteristics of diversity and integration [9]. Rurality is an important index to identify rural area space, and it is a representation of the differentiation between urban and rural areas [10-12]. From the perspective of land use transformation, the rurality evaluation system can be constructed, which can not only enrich the research content of the global land plan but also have great significance to expand the rurality index research.

In 1971 and 1981, the United Kingdom used census statistics to establish an "index of rurality." [13] It is widely used by rural researchers [14] and proved to be useful tools for understanding rural change. The determinants of rural populations may vary among countries with different socioeconomic backgrounds. Therefore, the choice of variables used to construct the index should be based on the background and socioeconomic structure of the research field 
[15]. In the past few years, many developed countries have developed several indices of rurality such as the Rurality Index of England and Wales [14], the Index of Relative Rurality of the United States [16], the Montana State University (MSU) Rurality Index [17], and the General Practice Rurality Index of Canada [18]. The use of the rurality index marks an important step forward and serves as a basis for the consistent identification and comparison of the rural environment. However, the evaluation index system is relatively single, and the level of economic development in rural areas of developed countries is generally high, so the above evaluation index system can hardly be applied to developing countries [19]. In the current context of urbanization, it is more meaningful to investigate the intensity level of rurality in a fixed area (contrary to the urban level) than to delimit the urban and rural spatial transition zone [20]. All regions can be seen as a single entity consisting of a combination of villages and cities. In this context, rurality index within the integrated framework reflects socioeconomic differences and allows comparability across regions [21]. Therefore, the investigation of rurality level in urban-rural integration areas is more operational, and it is more in line with the reality of rural development in China.

Rurality intensity level can be measured through rurality evaluation index system. At present, there are four main ideas for the construction of the rurality evaluation index system in China. The first idea is to construct the index system from the perspective of tourism by selecting the indicators having pure rural characteristics, the index of pure urban characteristics, and the positive indicator and the inverse indicator. For example, from the perspective of rural tourism, five elements, such as regional conditions, tourism resource base, tourism industry localization, community participation, and sustainable development, were selected to analyze the connotation of rurality [22]. Because of different understanding of rurality in different contexts, this idea is still insufficient, so it is necessary to adjust and supplement the index system by using the development of rural tourism to further improve the rurality evaluation index system.

The second idea holds that the selection of the rurality evaluation index system should fully reflect the social function of the countryside. For example, in the rurality evaluation index system for different rural development types, the pure rural indicators such as the rate of change of cultivated land, the rate of change of rural population, the employment ratio of the primary industry, the yield of agricultural land, and the productivity of agricultural labor are selected [23]. Different types of rural development may have the same or similar rurality index value. For example, there are some areas with weak rurality in agriculture-oriented counties and some areas with strong rurality in industrial-oriented and business-oriented counties. Therefore, some industries located in rural areas, such as high-tech tourism agriculture and business tourism services, have developed rapidly. They will make the rurality index value of some counties differ greatly from other similar areas, and the same rurality index value may correspond to different types of rural development. Therefore, the method is no longer applicable.
Based on urban-rural integration, the third idea is to select indicators having pure urban characteristics to construct the rurality evaluation index system. For example, based on the quality of life theory, the income and expenditure index system which represents the rurality from the aspects of rural living standard and living state was constructed. In order to measure the rurality intensity level and make it comparable in different regions, urban is regarded as the reference unit. This method expresses the rurality intensity level in reverse by using comparison with the urban social development. However, the quality of life is a comprehensive concept with material aspects and nonmaterial aspects involving economic, social, cultural, political, ecological, and other aspects [24]. The use of the substitution method represents the nonmaterial aspects of the quality of life only through the data of residents' expenditure (basic expenditure, social expenditure, service expenditure, and entertainment expenditure). Therefore, this method lacks considering material indicators.

Based on the integration of urban and rural areas, the last idea is to consider that both pure urban indicators and pure rural indicators should be comprehensively integrated in the rurality evaluation index system. For example, comprehensive rurality evaluation index system will be constructed by selecting indicators with rural characteristics, such as the proportion of the primary industry and per capita cultivated land area, to evaluate the rurality intensity level. It will also select three indicators with urban characteristics, such as per capita industrial output value, per capita income, and traffic location, to reflect the rurality intensity level [25]. However, this method only selects a representative index from four dimensions: economic structure, land structure, living standard, and location condition. The evaluation index is too single to represent the characteristics of each evaluation dimension. Moreover, the data used in the evaluation index system are basically from statistical data, and the authenticity of the data cannot be guaranteed, so this method has limitations.

There is no unified concept of rurality. Rurality refers to the characteristics of rural areas which are different from urban areas. The rural areas have their own unique productive, living, and ecological functions, while land is the carrier of rural production, life, and ecological function. Therefore, rurality evaluation research can be carried out through rural land use transformation [26]. Land use transformation can fully reflect the level of rural productivity, the degree of life development, and ecological protection. Among them, agricultural land is the most significant land type and landscape which is different from the urban [26]. Agriculture is the industrial basis of rural development and an important representation of rural characteristics [27]. In the town area, the characteristics of agricultural land can be used to reflect the type and scale of agricultural production. It then describes the characteristics of rural agriculture. Hence, the type, distribution, and quantity of agricultural land are important manifestations of rurality.

With the development of urbanization and industrialization, the rural construction land has been expanding, 
which is mainly reflected in the expansion of rural residential areas, the increase and improvement of roads and infrastructure. With the development of urban-rural integration, the urbanization level in rural areas will gradually increase, and the construction land area in rural areas will continue to increase, so the characteristics of rural areas will gradually decrease, and the corresponding rurality will gradually decrease [28]. The ecological function of the countryside mainly plays a role through land use types such as water body and forest. Therefore, the ecological function of the countryside can be reflected by the change of land use types such as water area and forest land. The stronger the rural ecological function is, the more obvious the rural characteristics are and the greater the rurality is [29].

Based on the above analysis, as a unit connecting the countryside and the city, the town area can well reflect the characteristics of the countryside and study the rural development from the microperspective [30-37]. As the carrier of rural landscape, rural production, and life, the characteristics of rural land use are also indicators of rural development. The land use transformation research adopts the land use change which integrates the time scale and historical background of social and environmental changes and can objectively reflect the authenticity of the data [38]. Therefore, it is more practically significant to construct a rurality evaluation system based on the perspective of land use transformation from three aspects: production, life, and ecology close to the actual situation of the countryside. This study selects the evaluation index from the aspects of production, life, and ecology close to the rural reality. Taking 25 towns in Lixia County and Shanghe County in Jinan city as the study area and using land use data and economic statistics data, the rurality evaluation system based on the land use transformation angle is constructed, the changes of the rurality index and intensity in the study area from 2009 to 2015 are calculated, and the natural, economic, and social factors affecting the rurality are analyzed. The remainder of this paper is structured as follows: Section 2 introduces research methods and data sources. Section 3 takes 25 towns in Lixia County and Shanghe County as an example, calculates rurality, and analyzes driving factors of rurality. Section 4 discusses characteristics, contributions, and shortcomings of the method in this paper. Section 5 provides the conclusion of this paper and the policy recommendations.

\section{Materials and Methods}

2.1. Study Area. Two counties in the suburbs of Jinan are selected as the study area, namely, Lixia County in the eastern suburb and Shanghe County in the northern suburb. This paper takes 25 towns in these two counties as the evaluation unit (see Figure 1). Lixia County is located in the east of Jinan city, close to Shizhong County in the city center, belongs to the core construction scope of Jinan city, and there are 13 towns in Lixia County (including Wendong, Yanshan, Qianfoshan, Baotuquan, Quanchenglu, Dongguan, Yaojia, Daminghu, Dianliu, Jiefanglu, Shunhualu, Longdong, and Zhiyuan) (see Figure 2(a)). Shanghe County is located in the northeast of Jinan city, which belongs to the outer suburbs and is the subcenter city of Jinan city, and there are 12 towns in Shanghe County (including Xushang, Yuhuangmiao, Yingang, Huairen, Lonsangsi, Zhenglu, Jiazhuang, Sunji, Shahe, Hanmiao, Zhangfang, and Baiqiao) (see Figure 2(b)).

At the end of 2015, the total household registration population of Lixia County was 603,300, the GDP was 107.07 billion yuan, the annual average wage of urban workers was 58,584 yuan, the per capita net income of rural residents was 21,153 yuan, and the total land area was $101.18 \mathrm{~km}^{2}$, of which agricultural land accounted for $44.92 \%$ [39]. At the end of 2015, the total household registration population of Shanghe County was 636,900 , the GDP was 17.92 billion yuan, the annual average wage of urban workers was 42,294 yuan, the per capita net income of rural residents was 12,674 yuan, and the total land area was $1161.81 \mathrm{~km}^{2}$, of which agricultural land accounted for $80.03 \%$ [40]. There are great differences between the two counties in terms of location, topography, economic base, and development orientation. Therefore, selecting these two counties is conducive to exploring the internal differences of rurality in a developing city, so as to better guide for the development of villages.

2.2. Data Sources. The period of study was between 2009 and 2015, and the administrative boundary was divided into 2019 administrative divisions (http://www.jinan.gov.cn/col/ col24699/index.html,2019-01-31), social and economic statistic data were collected from Jinan Bureau of Statistics (http://jntj.jinan.gov.cn/,2016-12-10), land use data were collected from the Resource and Environmental Science Data Center of Chinese Academy of Sciences (http://www. resdc.cn), spatial resolution was $30 \mathrm{~m}$, accuracy of each phase image reached more than $85 \%$, and land use types were interpreted by remote sensing data which included cultivated land, garden land, forest land, grassland, construction land, rural settlements, water, and other lands.

\subsection{Rurality Evaluation System}

2.3.1. Indicator Selection. This study divided the rurality evaluation system into three subsystems, rural production, rural life, and rural ecology, and selected 9 evaluation factors (see Table 1) [26, 41-43]. The multiple collinearity of the 9 evaluation factors was tested by using SPSS software. The degree of collinearity between variables was judged through the degree of tolerance (TOL), variance expansion factor (VIF), and conditional index (CI). The results of multiple collinearity diagnosis of the 9 indicators were $0.231 \leq \mathrm{TOL} \leq 0.907, \quad 1.102 \leq \mathrm{VIF} \leq 3.526, \quad$ and $1.113 \leq \mathrm{CI} \leq 10.409$. Therefore, there is no serious multiple collinearity between indicators, which can be used in the calculation of rural evaluation.

2.3.2. Weight Calculation. In the process of rurality evaluation, the weight of the evaluation index has an important influence on the rationality of the evaluation result [26]. The 


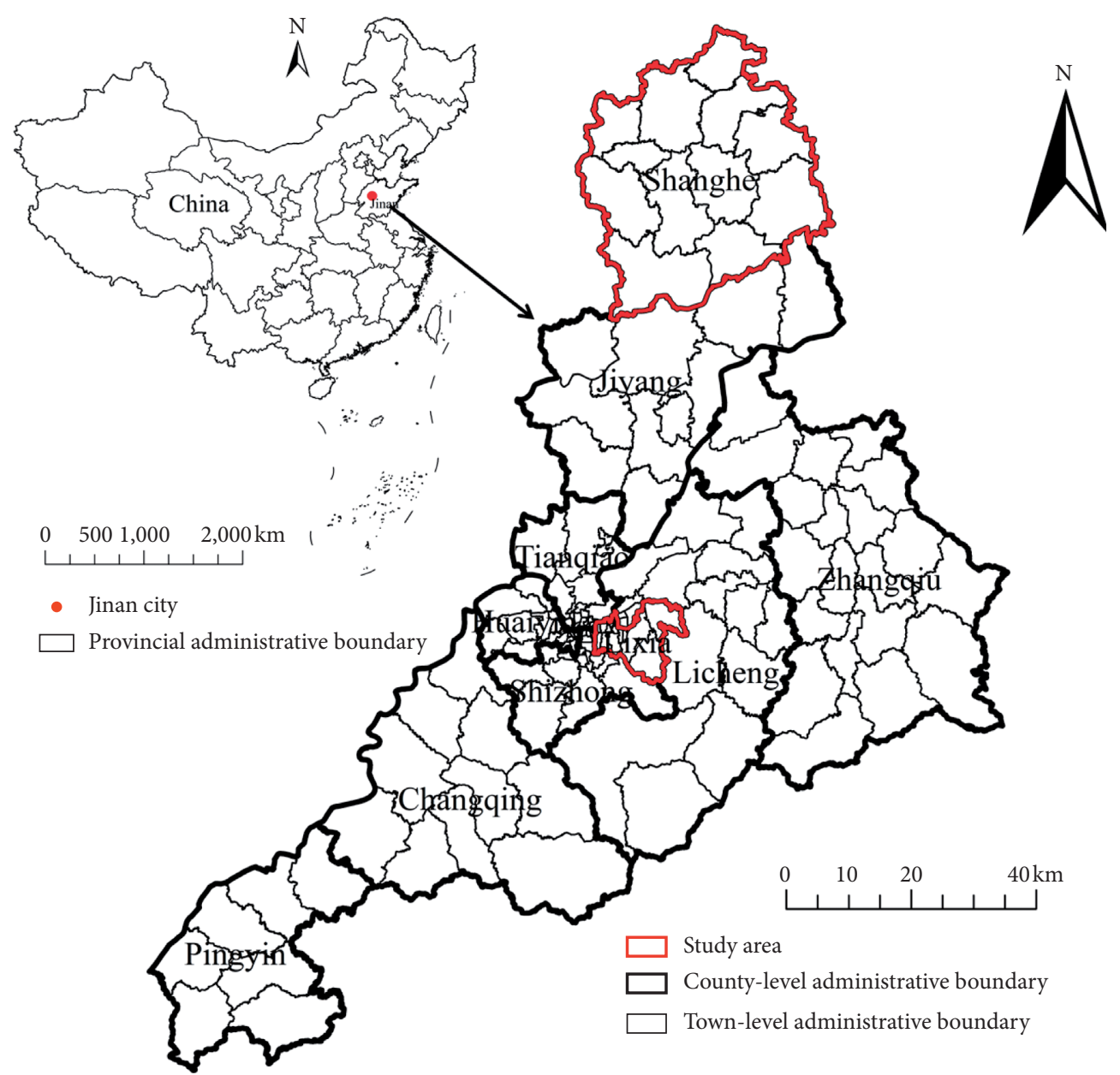

FIgURE 1: Location map of the study area.
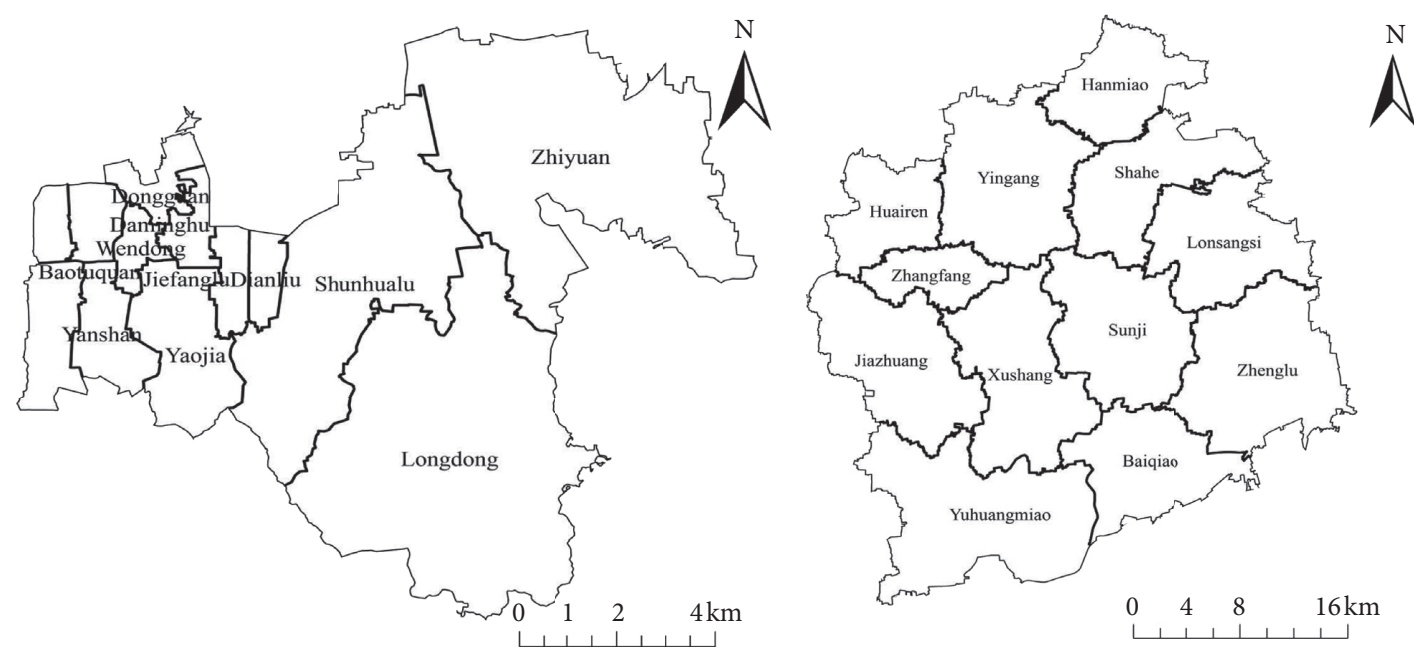

Town-level administrative boundary

$\square$ Town-level administrative boundary

(a)

(b)

Figure 2: (a) Administrative division map of Lixia County. (b) Administrative division map of Shanghe County. 
TABLE 1: Rural evaluation indicators.

\begin{tabular}{|c|c|c|c|c|}
\hline Rule hierarchy & Object hierarchy & Indicator meaning & $\begin{array}{l}\text { Nature of } \\
\text { indicators }\end{array}$ & $\begin{array}{c}\text { Total } \\
\text { weight }\end{array}$ \\
\hline \multirow{4}{*}{$\begin{array}{l}\text { Rural production } \\
(0.693)\end{array}$} & $\begin{array}{c}\text { Proportion of } \\
\text { agricultural land }(0.600)\end{array}$ & $\begin{array}{l}\text { Proportion of agricultural land to total land area, including } \\
\text { cultivated land, garden land, forest land, and pasture land. }\end{array}$ & + & 0.416 \\
\hline & $\begin{array}{l}\text { Rate of change in } \\
\text { cultivated land }(0.247)\end{array}$ & $\begin{array}{c}\text { Ratio of cultivated land area to initial cultivated land area at the } \\
\text { end of the period. }\end{array}$ & + & 0.171 \\
\hline & $\begin{array}{c}\text { Ratio of polyfarming } \\
(0.149)\end{array}$ & $\begin{array}{l}\text { Cultivated land area/rural residential area; this index is usually } \\
\text { used to measure the rural settlement occupation situation and its } \\
\text { reasonable degree. }\end{array}$ & + & 0.103 \\
\hline & $\begin{array}{l}\text { Rate of change in forest } \\
\text { land }(0.100)\end{array}$ & $\begin{array}{l}\text { Ratio of forest land area to initial forest land area at the end of the } \\
\text { period. }\end{array}$ & + & 0.070 \\
\hline \multirow[t]{2}{*}{ Rural life (0.101) } & $\begin{array}{l}\text { Rural construction } \\
(0.571)\end{array}$ & $\begin{array}{l}\text { Ratio of construction land other than urban land and rural } \\
\text { residential land to total construction land. }\end{array}$ & - & 0.058 \\
\hline & Rural settlements (0.258) & Proportion of rural settlements to total land area. & - & 0.026 \\
\hline \multirow{3}{*}{$\begin{array}{l}\text { Rural ecology } \\
(0.206)\end{array}$} & $\begin{array}{l}\text { Ratio of water area } \\
\quad(0.564)\end{array}$ & Proportion of water area to total land area. & + & 0.116 \\
\hline & $\begin{array}{l}\text { Rate of wetland } \\
\text { conservation }(0.321)\end{array}$ & Proportion of wetland to total land area. & + & 0.066 \\
\hline & $\begin{array}{l}\text { Rate of forestland } \\
\text { coverage }(0.187)\end{array}$ & Proportion of forestland to total land area. & + & 0.039 \\
\hline
\end{tabular}

methods of determining the weight of the rurality evaluation index system mainly include subjective empowerment, subjective and objective empowerment, and objective empowerment [44]. Hierarchical analysis has unique advantages in multifactorial comprehensive evaluation [45-47]. Therefore, the method of combining qualitative and quantitative analysis with the Delphi method is selected as the weight calculation method (see Table 1).

2.3.3. Rurality Index Evaluation Methods. Due to different meanings represented by the indicators, there were dimensional differences [26]. The dimensionless treatment of indicators is the main means to solve this problem [26]. Therefore, in the calculation process of rurality index, each indicator will be first standardized, and then the rurality index (RI) will be calculated by the linear weighting method:

$$
\mathrm{RI}=\sum_{i=1}^{n} W_{i} S_{i},
$$

where RI refers to the rurality index. $W_{i}$ refers to the weight of indicators, $S_{i}$ refers to standardized values for each indicator, and $i=1,2,3, \ldots, 9$; the greater the value is, the stronger the rurality character is and the weaker the urban character is [26].

Each indicator was converted by using the extremum method. The calculation processes are expressed in equations (2) and (3):

$$
\begin{aligned}
& S_{i}=\frac{\left[x_{i}-\min \left(x_{i}\right)\right]}{\left[\max \left(x_{i}\right)-\min \left(x_{j}\right)\right]}, \\
& S_{i}=\frac{\left[\max \left(x_{i}\right)-x_{i}\right]}{\left[\max \left(x_{i}\right)-\min \left(x_{i}\right)\right]},
\end{aligned}
$$

where $\max _{i}$ and $\min x_{i}$ refer to the maximum and minimum of indictor $i$.

\section{Results}

3.1. Results of Rurality Evaluation. From the perspective of land use transformation, the rurality evaluation system was designed to calculate the rurality index of 25 towns in Lixia County and Shanghe County in 2009 and 2015 (see Table 2). Overall, the rurality index of Shanghe County was lower than that of Lixia County in 7 years. The average rurality index of Shanghe County decreased from 1.055 in 2009 to 1.021 in 2015. The average rurality index in Lixia County increased from 1.736 in 2009 to 4.343 in 2015 . The rural development of Shanghe County fell behind compared with Lixia County. The average rurality index of Shanghe County in 2009 was lower than that of Lixia County in 2015. It can be seen that the rurality index gap between Shanghe County and Lixia County was very wide, and the change of standard deviation of the rurality index also reflected that the difference of rural development level within Lixia County was greater than that of Shanghe County, which indicates that the overall development level of Shanghe County was weak.

3.2. Rurality Intensity Classification. Based on the results of rurality index calculation, the rural characteristics of 25 towns can be divided into 5 grades according to the natural breakpoint method [26, 48, 49], namely, weak intensity (I) $(\mathrm{RI} \leq 0.971)$, relatively weak intensity (II) $(0.971<$ $\mathrm{RI} \leq 1.040)$, moderate intensity (III) $(1.040<\mathrm{RI} \leq 1.052)$, relatively strong intensity (IV) $(1.052<\mathrm{RI} \leq 01.105)$, and strong intensity $(\mathrm{V})(\mathrm{RI}>1.105)$.

Table 3 shows the rurality intensity changes in 25 town areas in two counties. In 2009, the rurality grade of Lixia County was dominated by weak intensity (84.62\%), and 2 towns belonged to strong intensity (15.38\%), but there was no relatively strong intensity, moderate intensity, or relatively weak intensity. The rurality of the county changed greatly in 2015, with a large proportion (76.92\%) still being 
TABLE 2: Rurality index statistics.

\begin{tabular}{lccccc}
\hline County & Year & Maximum value & Minimum value & Average value & Standard deviation \\
\hline \multirow{2}{*}{ Lixia } & 2009 & 12.241 & -0.001 & 1.736 & 0.310 \\
\multirow{2}{*}{ Shanghe } & 2015 & 56.454 & 0.000 & 4.343 & 0.572 \\
& 2009 & 1.117 & 0.947 & 1.055 & 0.084 \\
& 2015 & 1.218 & 0.914 & 1.021 & 0.083 \\
\hline
\end{tabular}

TABLE 3: Intensity level of rurality.

\begin{tabular}{|c|c|c|c|c|c|c|c|c|c|c|c|}
\hline \multirow[b]{2}{*}{ County } & \multirow[b]{2}{*}{ Year } & \multicolumn{2}{|c|}{ Strong $(\mathrm{V})$} & \multicolumn{2}{|c|}{ Relatively strong (IV) } & \multicolumn{2}{|c|}{ Moderate (III) } & \multicolumn{2}{|c|}{ Relatively weak (II) } & \multicolumn{2}{|c|}{ Weak (I) } \\
\hline & & Number & $\begin{array}{c}\text { Percentage } \\
(\%)\end{array}$ & Number & $\begin{array}{l}\text { Percentage } \\
(\%)\end{array}$ & Number & $\begin{array}{l}\text { Percentage } \\
(\%)\end{array}$ & Number & $\begin{array}{c}\text { Percentage } \\
(\%)\end{array}$ & Number & $\begin{array}{c}\text { Percentage } \\
(\%)\end{array}$ \\
\hline \multirow{2}{*}{ Lixia } & 2009 & 2 & 15.38 & 0 & 0 & 0 & 0 & 0 & 0 & 11 & 84.62 \\
\hline & 2015 & 3 & 23.08 & 0 & 0 & 0 & 0 & 0 & 0 & 10 & 76.92 \\
\hline \multirow{2}{*}{ Shanghe } & 2009 & 2 & 16.67 & 4 & 33.33 & 1 & 8.33 & 3 & 25.00 & 2 & 16.67 \\
\hline & 2015 & 2 & 16.67 & 2 & 16.67 & 0 & 0 & 3 & 25.00 & 5 & 41.67 \\
\hline
\end{tabular}

weak intensity and with three towns belonging to strong intensity (23.08\%), no relatively strong intensity, moderate intensity, or relatively weak intensity. In 2009, the proportion of relatively strong intensity was dominated (33.33\%) in Shanghe County, with 3 towns belonging to relatively weak intensity $(25.00 \%), 2$ towns belonging to strong intensity (16.67\%) and weak intensity (16.67\%), and 1 town belonging to moderate intensity. In 2015, weak intensity accounted for a large proportion (41.67\%), moderate intensity disappeared, strong intensity and relatively weak intensity were unchanged $(16.67 \%)$, and relatively strong intensity decreased by 2 (16.67\%). Changes of rurality intensity in Lixia County and Shanghe County were different. The rurality intensity of Lixia County has been dominated by the weak intensity in 2009 , accounting for $84.62 \%$, although the proportion has decreased to $76.92 \%$ by 2015 , but it still exceeds $75 \%$, indicating that the rurality of each town in Lixia County was low, and the urbanization level was high. In Shanghe County, the rurality intensity decreased greatly in 7 years, with relatively strong intensity in 2009 and weak intensity in 2015 (see Table 3).

The spatial and temporal characteristics of rurality intensity in Lixia County and Shanghe County can be found by comparing the rurality intensity changes. During 7 years, the rurality intensity level in the eastern part of Lixia County was higher, and the northwest was lower. The range of the rurality intensity level decreased, the distribution area of weak intensity was wider, and the rurality intensity level in the east was obviously higher than that in the northwest. It shows that the development of the eastern part of Lixia County was slightly behind the northwest, among which Dongguan town, Daming Lake town, Wendong town, and Qianfoshan town have the weakest rural characteristics, and the level of economic development in these towns was relatively high (see Figures 3(a) and 3(b)). However, the rurality intensity level in the north of Shanghe was higher, and the rurality intensity level in the middle was lower. Among them, Sunji town, which was near Xushang town, where the county government was located, changed the most, and the rurality intensity level dropped by 3 grades, from the original strong intensity to the relatively weak intensity (see Figures 4(a) and 4(b)).

\subsection{Rurality's Driving Factors' Analysis}

3.3.1. Economic Factors. Differences of economic development level will directly affect regional rurality differentiation [41]. Relevant indicators were selected to reflect the economic development level in the study area and to carry out the correlation analysis. The results showed that there was a negative correlation between the rurality index and the GDP at significant level 0.01 , and the correlation coefficient was -0.863 . It can be further confirmed that the rurality index based on land use transformation can reflect the rural economic development level, and the rurality index can be used to reveal the internal differences of rural development.

3.3.2. Social Factors. The rural development level was affected by and social development degree can be recognized from many aspects, including the location conditions of the town area, the infrastructure improvement level, the urbanization level, and the education popularization level [42]. The relationship between the rurality index and social factors was reflected by the distance from the center of the town government, the road construction level, the urbanization level, and the education level. The results showed that there was a negative correlation between the rurality index and the distance from the center of the town government, the road construction level, the urbanization level, and the education level at significant level 0.01 , and the correlation coefficient was $-0.648,-0.562,-0.697$, and -0.701 , respectively. Therefore, the better the location conditions are, the greater the road area is, the higher the urbanization level is, the higher the education level is, and the lower the rurality index is.

3.3.3. Natural Factors. The rurality index designed in this study was closely related to land use types and land use patterns. Moreover, differences in natural factors directly 

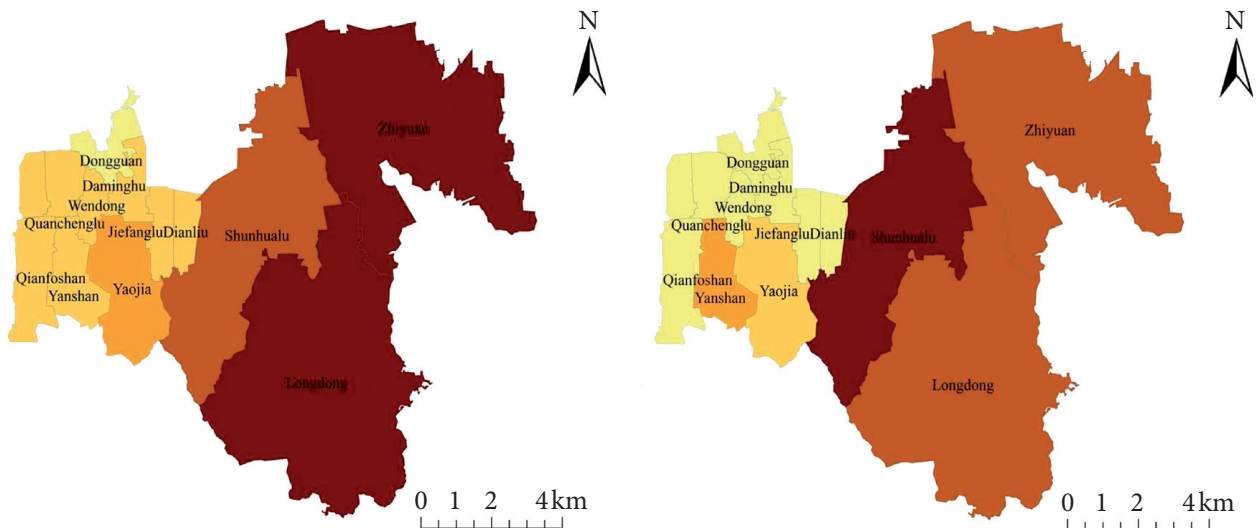

$$
\begin{gathered}
\text { Lixia County RI } \\
-0.000883 \\
-0.000882-0.000000 \\
0.000001-0.109690 \\
0.109691-0.187597 \\
0.187598-12.240912
\end{gathered}
$$

$$
\begin{aligned}
& \text { Lixia County RI } \\
& 0.000000 \\
& 0.000001-0.137002 \\
& 0.137003-0.149837 \\
& 0.149838-1.179854 \\
& \square-179855-53.830028
\end{aligned}
$$

(a)

(b)

FiguRe 3: (a) Rurality intensity distribution of Lixia County in 2009. (b) Rurality intensity distribution of Lixia County in 2015.
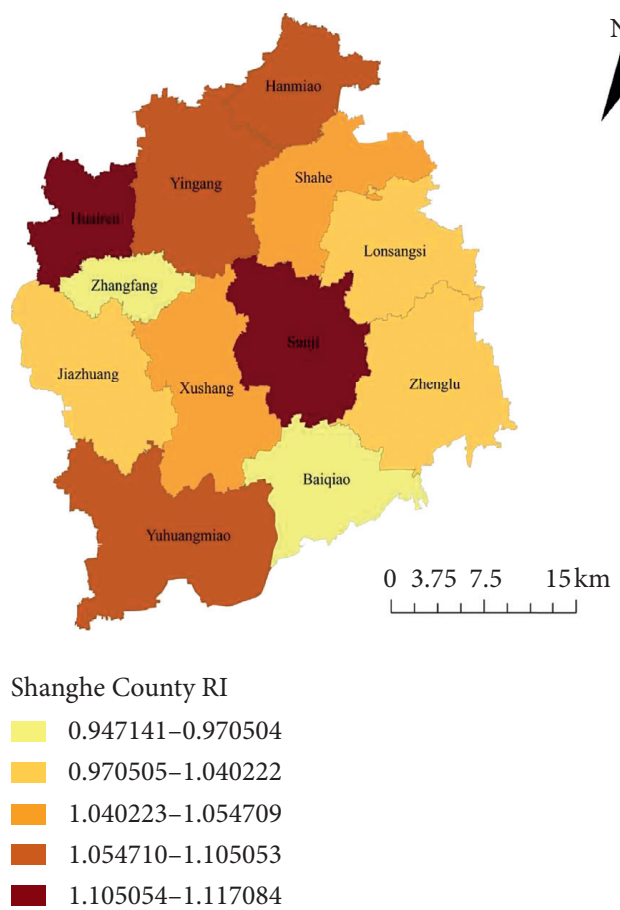

(a)

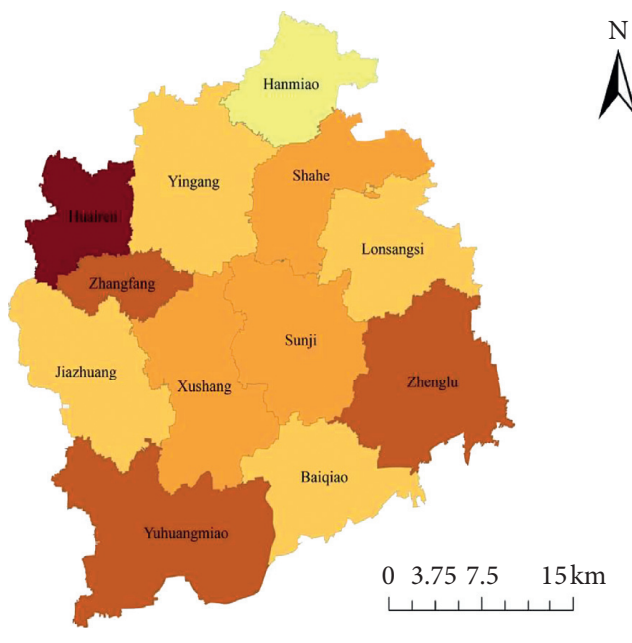

Shanghe County RI

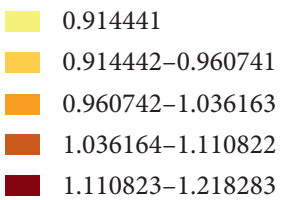

(b)

Figure 4: (a) Rurality intensity distribution of Shanghe County in 2009. (b) Rurality intensity distribution of Shanghe County in 2015.

affected land use patterns [44]. Natural factors included topography, soil, climate, and hydrology. Because Lixia County and Shanghe County have great difference in terrain characteristics, Shanghe County belonged to North China alluvial plain. Terrain of Lixia County was high in the south and low in the north, with an average elevation of 102 meters, so elevation factor of towns in Lixia County was analyzed in order to examine the relationship with rurality index. The result showed that the average elevation of towns in Lixia County was significantly correlated with the rural index at 0.05 , and the correlation coefficient was 0.675 in 2015. It showed that the rural index of towns in Lixia County 
was significantly affected by altitude. The rurality index of Dongguan town with the lowest average elevation was the lowest, while the average elevation of Longdong town was the highest, and the corresponding rurality index was the highest. It can be seen that the development level of the town area was easy to be affected by the elevation difference in the area with great terrain change, the rurality index with higher elevation was also higher, and the rural development level also relatively fell behind.

\section{Discussion}

There was no uniform standard for the cognition of rurality connotation or the calculation of the rurality index [23]. The present study focuses on the evaluation index system of rural characteristics, the evaluation index system of pure urban characteristics, and the comprehensive evaluation index system integrating pure rural characteristics and pure urban characteristics. The pure rurality evaluation index system will be affected by different types of rural development, resulting in the same or similar rurality index value [22]. However, although the evaluation index system of pure urban characteristics can be established from the perspective of data availability, the "substitution method" is used to represent the nonmaterial factors of the quality of life only through the data of residents' expenditure. Therefore, the method lacks the evaluation of rurality considering the material index [23]. Although the comprehensive evaluation index system covering the characteristics of pure rural and pure urban takes into account the integration of urban and rural areas, however, it is difficult to obtain indicators that reflect purely rural or urban characteristics; in addition, most of the data used in the evaluation index system come from statistical data, and the authenticity of the data cannot be guaranteed [24]. Therefore, considering that rural development is closely related to land use transformation, rurality evaluation index system based on land use transformation can avoid the deficiency of statistical data distortion. The measurement unit of the rurality index based on land use transformation can be extended directly to town and village scale. It can help to deepen the rurality index research.

This paper explored the rurality evaluation index system from the perspective of land use transformation and carried out the rurality evaluation system for typical towns in Jinan city. Evaluation results were consistent with local economic development. The rurality index of towns in Lixia County in the close suburbs of Jinan city was obviously faster than that of towns in Shanghe County in the far suburbs of Jinan city. The change in the rurality index was also consistent with the expansion direction of Jinan city. In the new round of urban planning, Jinan city implements the urban space development strategy in order to guide the layout of the city along the east and west wings, strictly control the spread of the city to the southern mountainous areas, timely cross the Yellow River to the north, and optimize the function of the old urban areas. Lixia County was listed in the urban area of Jinan city construction center. Its urbanization process has been accelerated year by year, the rurality index has declined rapidly, and the rurality intensity level has been reduced continuously. Due to the poor location condition, urbanization development of Shanghe County was backward, and it has little change in rurality intensity. Therefore, the evolution of rurality was also closely related to the direction of urban expansion and the speed of development.

Rurality is the result of multifactorial synthesis. Therefore, the index system of this study still needs to be further refined and improved. We can comprehensively construct the rurality index evaluation system from the dimensions of economic structure, land use transformation, living standard, and location conditions. It is more helpful to improve the understanding of rurality and further enrich the research of the rurality evaluation index system.

\section{Conclusions}

Taking 25 towns in Lixia County and Shanghe County in the suburbs of Jinan city as the study area and using the land use data and the economic statistics data in 2009 and 2015, the rurality index evaluation system based on the land use transformation was constructed, 9 rurality evaluation indicators were selected, the changes of the rurality index and intensity were calculated, and the driving factors of the rurality were analyzed.

Based on three aspects of rural production, rural life, and rural ecology, the rurality evaluation system based on the land use transformation was constructed. The results showed that the mean values of the rurality index of Lixia County and Shanghe County were 0.355 and 0.684 , respectively, in 2009. In 2015, the mean values were 0.260 and 0.540 , respectively. From 2009 to 2015 , the rurality difference among towns in Lixia County decreased, the rurality difference among towns in Shanghe County increased, the rurality intensity level of Lixia County was lower than that of towns in Shanghe County, and the rurality index gap between the towns in the two counties was increasing. The change characteristics of the rurality index were basically consistent with the economic development level of the towns in the two counties. The rural characteristics of Lixia County were gradually decreasing, the reduction rate was faster than Shanghe County, the gap of the rural development level within Shanghe County was decreasing, and the polarization degree of rural development in Lixia County was gradually increasing.

Based on the results of rurality index calculation, the rural characteristics of 25 towns can be divided into 5 grades according to the natural breakpoint method [39, 49], namely, weak intensity, relatively weak intensity, moderate intensity, relatively strong intensity, and strong intensity. In 2009, the rurality grade of Lixia County was dominated by weak intensity $(84.62 \%)$, and the rurality of the county changed greatly in 2015, with a large proportion $(76.92 \%)$ still being weak intensity. In 2009, the proportion of relatively strong intensity was dominated (33.33\%) in Shanghe County; in 2015, weak intensity accounted for a large proportion $(41.67 \%)$. Changes of rurality intensity in Lixia County and Shanghe County were different. The change of the rurality intensity level further indicates that the 
urbanization level of Lixia County was higher than that of Shanghe County. However, rural development in Shanghe County was also accelerating during the 7 years.

Analysis of the relationship between the rurality index and natural, economic, and social factors showed that there was a significant correlation between the rurality index and geographical elevation, GDP, and the distance from the center of the town government, the road construction level, the urbanization level, and the education level. It showed that the rurality evaluation index based on land use transformation can well reflect rural development characteristics. In regions with better natural, economic, and social conditions, rural development will be faster, rurality index will be lower, and rural characteristics will be decreasing.

\section{Data Availability}

The social and economic statistic and land use data used to support the findings of this study were supplied by Jinan Bureau of Statistics and Resource and Environmental Science Data Center of Chinese Academy of Sciences under license and so cannot be made freely available. Requests for access to these data should be made to Jinan Bureau of Statistics, http://jntj.jinan.gov.cn/; Resource and Environmental Science Data Center of Chinese Academy of Sciences, http://www.resdc.cn.

\section{Conflicts of Interest}

The authors declare that they have no conflicts of interest.

\section{Acknowledgments}

This study was supported by the National Natural Science Foundation of China (Grant no. 41501606), Humanities and Social Science Research Project of Ministry of Education of China (Grant no. 13YJC790182), the Foundation of Key Laboratory of Urban Agriculture in East China, Ministry of Agriculture (Grant no. HD201803), State Scholarship Fund of China (Grant no. 201908610060), the Shaanxi Provincial Soft Science Program Fund (Grant no. 2019KRM157), Special Research Project of Education Department of Shaanxi (Grant no. 19JK0437), and the Research Institute of New Urbanization and Human Settlement in Shaanxi Province (Grant no. 1608219015).

\section{References}

[1] J. Yang, J. Su, J. Xia, C. Jin, X. Li, and Q. Ge, “The impact of spatial form of urban architecture on the urban thermal environment: a case study of the Zhongshan District, Dalian, China," IEEE Journal of Selected Topics in Applied Earth Observations and Remote Sensing, vol. 11, no. 8, pp. 27092716, 2018.

[2] H. Long and S. Tu, "Rural restructuring: theory, approach and research prospect," Acta Geographica Sinica, vol. 72, no. 4, pp. 563-576, 2017.

[3] Y. Liu, The New Chinese Rural Construction Geographical Theory, Science Press, Beijing, China, 2011.
[4] L. Ma, H. Long, S. Tu, Y. Zhang, and Y. Zheng, "Farmland transition in China and its policy implications," Land Use Policy, vol. 92, Article ID 104470, 2020.

[5] K. Chen, H. Long, L. Liao, S. Tu, and T. Li, "Land use transitions and urban-rural integrated development: theoretical framework and China's evidence," Land Use Policy, vol. 92, Article ID 104465, 2020.

[6] Y. Wu, E. C. M. Hui, P. Zhao, and H. Long, "Land use policy for urbanization in China," Habitat International, vol. 77, pp. 40-42, 2018.

[7] Y. Qu and H. Long, "The economic and environmental effects of land use transitions under rapid urbanization and the implications for land use management," Habitat International, vol. 82, pp. 113-121, 2018.

[8] H. Long and Y. Qu, "Land use transitions and land management: a mutual feedback perspective," Land Use Policy, vol. 74, pp. 111-120, 2018.

[9] Y. Liu, R. Yang, H. Long, J. Gao, and J. Wang, "Implications of land-use change in rural China: a case study of Yucheng, Shandong province," Land Use Policy, vol. 40, pp. 111-118, 2014.

[10] J. Yang, A. Guo, Y. Li, Y. Zhang, and X. Li, "Simulation of landscape spatial layout evolution in rural-urban fringe areas: a case study of Ganjingzi district," GIScience \& Remote Sensing, vol. 56, no. 3, pp. 388-405, 2019.

[11] J. Yang, W. Liu, Y. Li, X. Li, and Q. Ge, "Simulating intraurban land use dynamics under multiple scenarios based on fuzzy cellular automata: a case study of Jinzhou district, Dalian," Complexity, vol. 2018, no. 4, 17 pages, Article ID 7202985, 2018.

[12] J. Yang, J. Su, F. Chen, P. Xie, and Q. Ge, "A local land use competition cellular automata model and its application," International Journal of Geo Information, vol. 5, no. 7, pp. 74-86, 2016.

[13] P. Cloke and G. Edwards, "Rurality in England and Wales 1981: a replication of the 1971 index," Regional Studies, vol. 20, no. 4, pp. 289-306, 1986.

[14] V. Harrington and D. O’Donoghue, "Rurality in England and Wales 1991: a replication and extension of the 1981 rurality index," Sociologia Ruralis, vol. 38, no. 2, pp. 178-203, 1998.

[15] L. G. Hart, E. H. Larson, and D. M. Lishner, "Rural definitions for health policy and research," American Journal of Public Health, vol. 95, no. 7, pp. 1149-1155, 2005.

[16] P. J. Cloke, "An index of rurality for England and Wales," Regional Studies, vol. 11, no. 1, pp. 31-46, 1977.

[17] C. Weinert and R. J. Boik, "MSU rurality index: development and evaluation," Research in Nursing \& Health, vol. 18, no. 5, pp. 453-464, 1995.

[18] S. Olatunde, E. R. Leduc, and J. Berkowitz, "Different practice patterns of rural and urban general practitioners are predicted by the general practice rurality index," Canadian Journal of Rural Medicine: The Official Journal of the Society of Rural Physicians of Canada, vol. 12, no. 2, pp. 73-80, 2007.

[19] J. R. Blunden, W. T. R. Pryce, and P. Dreyer, "The classification of rural areas in the European context: an exploration of a typology using neural network applications," Regional Studies, vol. 32, no. 2, pp. 149-160, 1998.

[20] X. L. Zhang, "On discrimination of rural definitions," Acta Geographica Sinica, vol. 53, no. 4, pp. 365-371, 1998.

[21] P. Li, S. Liu, and L. Sun, "Spatial-temporal changes of rurality driven by urbanization and industrialization: a case study of the Three Gorges Reservoir Area in Chongqing, China," Habitat International, vol. 51, pp. 124-132, 2016. 
[22] S. Feng and R. Sha, "Evaluation model of countryside tourism's rural Feature: a case study of Wuyuan in Jiangxi province," Geographical Research, vol. 3, pp. 616-624, 2007.

[23] H. Long, Y. Liu, and Z. Jian, "Assessment of rural development types and their rurality in eastern coastal China," Acta Geographica Sinica, vol. 64, no. 4, pp. 426-434, 2009.

[24] G. Ren, L. Liu, Q. Guan, and J. Sun, "Rurality evaluation and spatial autocorrelation type classification based on quality of life in metropolitan suburbs," Transactions of the Chinese Society of Agricultural Engineering (Transactions of the CSAE), vol. 35, no. 7, pp. 264-275, 2019.

[25] D. Han, J. J. Qiao, and Y. L. Ma, "Rurality spatial differentiation mechanism in the new era based on the perspective of spatial interface: a case study of Gongyi City, Henan Province," Progress in Geography, vol. 37, no. 5, pp. 655-666, 2018.

[26] Y. Feng, Z. Liang, Y. Zhong, and F. Wang, "Spatial and temporal change of rurality in towns based on land use: a case of panyu district and conghua district in Guangzhou," Scientia Geographica Sinica, vol. 38, no. 9, pp. 1499-1507, 2018.

[27] J. Han, W. Ge, Z. Hei et al., "Agricultural land use and management weaken the soil erosion induced by extreme rainstorms," Agriculture, Ecosystems \& Environment, vol. 301, Article ID 107047, 2020.

[28] M. Xia, Y. Zhang, Z. Zhang, J. Liu, W. Ou, and W. Zou, "Modeling agricultural land use change in a rapid urbanizing town: linking the decisions of government, peasant households and enterprises," Land Use Policy, vol. 90, Article ID 104266, 2020.

[29] T. Fitzgerald, Y. Kuwayama, S. Olmstead, and A. Thompson, "Dynamic impacts of U.S. energy development on agricultural land use," Energy Policy, vol. 137, Article ID 111163, 2020.

[30] S. R. Henderson, "Managing land-use conflict around urban centres: Australian poultry farmer attitudes towards relocation," Applied Geography, vol. 25, no. 2, pp. 97-119, 2005.

[31] D. Tang, H. Liu, E. Song, and S. Chang, "Urban expansion simulation from the perspective of land acquisition-based on bargaining model and ant colony optimization," Computers, Environment and Urban Systems, vol. 82, Article ID 101504, 2020.

[32] T. Liu, D. Huang, X. Tan, and F. Kong, "Planning consistency and implementation in urbanizing China: comparing urban and land use plans in suburban Beijing," Land Use Policy, vol. 94, Article ID 104498, 2020.

[33] M. Sabir, A. Torre, and H. Magsi, "Land-use conflict and socio-economic impacts of infrastructure projects: the case of Diamer Bhasha Dam in Pakistan," Area Development and Policy, vol. 2, no. 1, pp. 40-54, 2017.

[34] D. Jensen, T. Baird, and G. Blank, "New landscapes of conflict: land-use competition at the urban-rural fringe," Landscape Research, vol. 44, no. 4, pp. 418-429, 2019.

[35] I. J. Kathrine, "Land-use conflicts between reindeer husbandry and mineral extraction in Finnmark, Norway: contested rationalities and the politics of belonging," Polar Geography, vol. 39, no. 1, pp. 58-79, 2016.

[36] G. D. Luca and P. G. Sekeris, "Land inequality and conflict intensity," Public Choice, vol. 150, pp. 119-135, 2012.

[37] R. Froese and J. Schilling, "The nexus of climate change, land use, and conflicts," Current Climate Change Reports, vol. 5, no. 1, pp. 24-35, 2019.

[38] J. D. Evans, J. B. Kirkpatrick, and K. L. Bridle, “A reciprocal triangulation process for identifying and mapping potential land use conflict," Environmental Management, vol. 62, no. 4, pp. 777-791, 2018.
[39] Jinan Bureau of Statistics, Jinan Statistical Yearbook 2009, Statistical Press, Jinan, China, 2010.

[40] Jinan Bureau of Statistics, Jinan Statistical Yearbook 2015, Statistical Press, Jinan, China, 2016.

[41] Y. Sun, Y. Cheng, and P. Zhang, "Spatio-temporal dynamics of rurality in Northeast China," Geographical Research, vol. 34, no. 10, pp. 1864-1874, 2015.

[42] X. Nie, P. Shi, X. Zhang, R. Lv, Y. Zhu, and W. Wei, "Research on rurality evaluation and the driving mechanism in arid regions of northwest China: a case study of Wuwei City in Gansu province," Scientia Geographica Sinica, vol. 37, no. 4, pp. 585-594, 2017.

[43] X. Zhang, L. Fan, and L. Wu, "Jin Qiming's research on rural settlement geography of Jiangsu province," Rural Planning and Construction, vol. 3, pp. 11-15, 2015.

[44] H. Meng, T. Li, Z. Yu, and F. Li, "Rurality and acorrelation analysis of the county economy in Anhui Province," Economic Geography, vol. 33, no. 4, pp. 144-148, 2013.

[45] C. Li, X. Gao, B. He, J. Wu, and K. Wu, "Coupling coordination relationships between urban-industrial land use efficiency and accessibility of highway networks: evidence from beijing-tianjin-hebei urban agglomeration, China," Sustainability, vol. 11, Article ID 1446, 2019.

[46] C. Li, K. Wu, and X. Gao, "Manufacturing industry agglomeration and spatial clustering: evidence from Hebei Province, China," Environment, Development and Sustainability, vol. 22, no. 4, pp. 2941-2965, 2020.

[47] C. Li, X. Gao, J. Wu, and K. Wu, "Demand prediction and regulation zoning of urban-industrial land: evidence from Beijing-Tianjin-Hebei Urban Agglomeration, China," Environmental Monitoring and Assessment, vol. 191, no. 7, p. 42, 2019.

[48] C. Li, K. Wu, and J. Wu, "Urban land use change and its socioeconomic driving forces in China: a case study in Beijing, Tianjin and Hebei region," Environment, Development and Sustainability, vol. 20, no. 3, pp. 1405-1419, 2018.

[49] G. Qin, P. Zhang, X. Hou, S. Wu, and Y. Wang, "Risk assessment for oil leakage under the common threat of multiple natural hazards," Environmental Science and Pollution Research, vol. 27, no. 14, pp. 16507-16520, 2020. 